\title{
The Effect of COVID-19 Pandemic on The Anxiety Levels of Radiology Experts and Clinical Functioning
}

\author{
Hilal Altas ${ }^{1(\mathrm{ID})}$, Sedat Bostan $^{2(\mathrm{ID})}$ \\ ${ }^{1}$ Department of Radiology, Faculty of Medicine, Ordu University, Ordu, Turkey \\ ${ }^{2}$ Department of Health Management, Faculty of Health Sciences, Ordu University, Ordu, Turkey
}

Copyright@ Author(s) - Available online at https://dergipark.org.tr/en/pub/mbsjohs

Content of this journal is licensed under a Creative Commons Attribution-NonCommercial 4.0 International License,

Received: 28 January 2021, Accepted: 25 March 2021, Published online: 30 April 2021

(C) Ordu University Institute of Health Sciences, Turkey, 2021

\begin{abstract}
Objective: The severe acute respiratory syndrome corona virus 2 (SARS-CoV-2) is a novel human corona virus rapidly spread all over the world and caused Corona Virus Disease-2019 (COVID-19) pandemic. Radiology clinics were reorganised according to the changes in health system in order to combat with this epidemic. We aimed to detect the changes in the functioning of radiology clinics and to state anxiety levels and relevant factors that induced anxiety in radiologists.

Methods: The research is a descriptive study, population constitudes, radiology residents, specialists and scholars actively working in Turkey during COVID-19 pandemic. The data of the study were collected digitally, through the clinical activity scale and Back anxiety scale questionnaires created over the internet. The data collection period started on 18.04.2020 and ended on 8.6.2020.

Results: Eightysix radiologists completed the survey. It was understood that the radiologists working during the pandemic had a high level of personal anxiety and worked under stress $(3,74)$. A weak linear relationship was found between the changes in the functioning of radiology clinics and the personal concerns of radiology physicians at the $\mathrm{p}=0.05$ error level $(0.224)$. They stated that unnecessary thorax computed tomography (CT) demands increased $(4,51)$ and they made the most thorax CT evaluation in the daily routine $(4,42)$.

Conclusion: In our study, it was shown that there were significant changes in the functioning of radiology clinics especially related with increased thorax CT scans at the beginning of the COVID-19 pandemic and that the anxiety levels of radiologists increased due to the pandemic.
\end{abstract}

Key words: COVID-19, Radiologist, Anxiety

Suggested Citation Altas H., Bostan S. The effect of COVID-19 pandemic on the anxiety levels of radiology experts and clinical functioning. Mid Blac Sea J Health Sci, 2021; 7(1):49-56

\section{Address for correspondence/reprints:}

Hilal Altas

Telephone number: +90 (544) 6608966

E-mail: hilalaltas@gmail.com

\section{Introduction}

The severe acute respiratory syndrome corona virus 2 (SARS-CoV-2) is a new member of corona virus family, that emerged in Wuhan, China and led to an outbreak of viral pneumonia in December 2019 $(1,2)$. This novel human corona virus rapidly spread all over the world and caused Corona Virus Disease2019 (COVID-19) pandemic. The World Health Organization declared COVID-19 as a global health emergency on March 11, 2020 (3). On the same day, the first COVID-19 case is officially reported in Turkey. Although the public authorities took urgent actions such as curfews over 65 and under 18 years, travel restrictions, closure of schools, COVID-19 has spread rapidly in Turkey (4). COVID-19 mainly 
transmitted through air droplets, aerosols and direct contact. The asymptomatic carriers have been reported as the main cause of rapid spread (5-7). By October 2020, 12,194,778 tests were performed, a total of 343,955 cases were detected and the number of deaths has been recorded so far is 9,153 in Turkey (8).

The health system in Turkey was restructured to combat the epidemic due to the rapid spread of the COVID-19 epidemic all over the world and the increase in the number of serious patients and mortality rates. Like other departments, radiology clinics were immediately reorganised according to new conjuncture. Radiologists have been assigned in services and polyclinics in the care of corona patients. Although chest CT scan is not recommended for the diagnosis of COVID-19 during the pandemic period, it has yielded important findings for detecting the disease at the first application and used in the diagnosis of patients in conjunction with RT-PCR (Reverse Transcriptase Polymerase Chain Reaction) (9). As a consequence, the increase in thoracic imaging has also significantly increased the radiologist's workload.

Health carrier workers -especially the front-line staff- were psychologically affected due to the highrisk viral contamination for themselves and also for their families. Recent studies have shown that emotional distress such as anxiety, depression and insomnia have increased during COVID-19 pandemic in health carrier workers $(10,11)$. The impact of the COVID-19 pandemic on healthcare organizations and healthcare workers has significantly affected the working order. In another study from Turkey, regarding clinical functioning and anxiety levels in neurosurgery clinics, it is shown that anxiety levels in neurosurgeons have increased and workflow of clinics have changed distinctly (12).

In our study, we aimed to detect the change in the functioning of radiology clinics and radiologist's way of working during COVID-19 pandemic. Also, we aimed to state anxiety levels and relevant factors that induced anxiety in radiologists.

\section{Methods}

This study was approved by the medical ethics committee of our institution (Approval Number: 2020/65) and the Republic of Turkey Ministry of Health, COVID-19 Scientific Research Committee. Our study is a survey study based on volunteerism.

\section{Research Universe and Sample}

The research is a descriptive study, and the data were collected by quantitative method. The research population constitutes, radiology residents, specialists and scholars actively working in Turkey during COVID-19 pandemic. Due to the restraints, the data of the study were collected digitally, through the clinical activity scale and back anxiety scale questionnaires created over the internet. Announcements were made on social media networks and personal communications were established for participation in the survey. Sampling management was used in data collection for easy data collection since researchers do not have the opportunity to identify the participants in the digital environment.

The data collection period started on 18.04.2020 and ended on 8.6.2020. During this time, 86 valid questionnaires were reached. This number was found sufficient to reflect the views of radiologists under pandemic conditions.

\section{Data Collection Tools}

The data of the study consists of three parts: the questionnaire form demographic information, "COVID-19 Pandemic Radiology Clinic Activity Scale" and "Back Anxiety Scale".

\section{Demographic Information}

It consists of two open-ended questions, together with the personal characteristics of physicians, the types of hospitals they work in, their exposure to the COVID-19 outbreak and their service provision.

\section{Scale \\ COVID-19 Pandemic Radiology Clinic Activity}

The scale was prepared by obtaining information about the pandemic, literature review, preliminary interviews with the radiology clinic chiefs and taking the opinions of the relevant academicians about the scope and structuring of the questions. SPSS program was used in the validity and reliability analysis of the scale. Factor analysis was conducted to understand the construct validity of the items of the scale. Validity is the degree to which a test or scale measures what is intended to be measured (Coşkun et al 2017). In the scale prepared as a total of 29 questions, five statements were removed because factor loads were low or inconsistent during factor analysis. The scale was validated as 24 expressions. Kaiser-Meyer-Olkin (KMO) test was performed for the sample number and it was found to be 0.724 . In addition, to find out whether the correlation between items were significant, Barlett's sphericity test results were examined and it was found to be significant at 
the 0.001 level (Approx.Chi-Square: 961,675 / df: 253 / sig: 0.000). In order to size the items, the "principal components" method and the "Verimax" rotation process were applied. The scale items were found to have factor loads between 0.528 and 0.867 . The scale was collected under 3 factors. These factors are The functioning of the radiology clinic ( 8 statements), Personal Anxiety (5 statements), Clinical Approach and Combat (11 statements) factors. The explanation level of the variance of the factors that make up the scale was calculated as $52.9 \%$.

\section{The Back Anxiety Scale}

It was validated with factor analysis under a single factor. The reliability analysis of the scales was calculated with the Cronbach's Alpha coefficient. The Cronbach's Alpha coefficient of the scales was calculated as 0.824 and 0.917 , respectively. The data were analyzed with frequency, significance and correlation tests with SPSS package program. In evaluating the average of frequency values; 1-2.33 low 2.34-3.66 medium and 3.67-5 high levels.

\section{Statistical analysis}

The data were analyzed using SPSS 25.0 package software. Continuous variables are expressed as mean, standard deviation, and median (minimummaximum) values, and categorical variables are expressed as numbers and percentages. The normal distribution of the data was examined using ShapiroWilk and Kolmogorov-Smirnov tests. When parametric test assumptions were met, independent ttest and one-way analysis of variance were used for the comparison of the differences between independent groups. When the parametric test assumptions were not met, Mann-Whitney U test was used in comparison of independent group differences. Logistic Regression analysis was used to determine the risk factors affecting the dependent variable. In all analyzes, $\quad \mathrm{p}<0.05$ was considered statistically significant.

\section{Ethics of the Study}

The study was approved by the Ordu University, Non-Interventional Ethics Committee (18-KAEK053) and the institutions where the study was conducted. The purpose of the study was explained to the participants, and the participants were assured that their responses would be anonymous and would be used only in scientific research; they were also informed that they could withdraw at any point during the interview. Verbal and written consents were obtained from the participants. The study was performed as per the "Informed Consent,
Confidentiality and Protection of Privacy and Respect for Autonomy" principles and the Helsinki Declaration. The required permissions were obtained from those who confirmed the validity and reliability of the Turkish version of the scale. The data were collected within 30 minutes via face-to-face interviews. The parents were interviewed in different environments to prevent influence from each other.

\section{Results}

Eightysix radiologists completed the survey. Of the radiologists participating in the study, 55.8\% are male, $48.8 \%$ are 39 years old and younger, $33.7 \%$ have worked 6-10 years in the profession, $47.7 \%$ work in a university hospital, $53.5 \%$ work as a radiologist. Although $60.5 \%$ of them are not pandemic hospitals, they work in hospitals where covid patients are treated. The research findings of this study and descriptive variables of participants are given in Table 1.

$80.2 \%$ of radiology physicians encountered patients infected with COVID-19 and provided services to these patients. 25 radiologists had the COVID-19 test and 3 physicians tested positive. Two of them recovered, one physician was in quarantine.

The data of the scale, which was developed to understand the effect of the pandemic on the functioning of radiology clinics during the ongoing pandemic, are given in Table 2 . In order to understand the details of the data, the frequency distributions of the participants' participation levels in the expressions of the scale were also written in the table. When the table is examined, it is understood that there is a moderate differentiation in the functioning of the radiology clinic $(3,37)$ during the pandemic process. Radiology physicians stated that radiology clinics could not continue routine patient admissions (3.47), they postponed routine ultrasound (3.61) and interventional radiology procedures (3.55), and continued the procedures of emergency and cancer cases (4.03). They also stated that the diagnostic processes of outpatients were interrupted (3.85) and they tried to help patients with telemedicine methods (3.86) at medium and high levels.

It was understood that the radiologists working during the pandemic had a high level of personal anxiety and worked under stress $(3,74)$. Radiologists: Risk of developing COVID-19 disease (3.83), high expectations of colleagues about the diagnosis of COVID-19 with thoracic CT (3.56), ultrasonography (USG) applications (4.09), rapid deterioration in the thorax CT of COVID-19 patients $(3,69)$ and being assigned to COVID-19 patient processes (3.49), they 
stated that they experienced moderate-to-high levels of anxiety and stress.

During the ongoing pandemic process, there has been a moderate change in the clinical approaches of radiologists $(3,67)$ to combat the pandemic at the clinical level. Radiology experts stated that in-house informing about the pandemic was done effectively $(3,43)$; have sufficient personal equipment $(3,20)$; stated that they used personal protective equipment correctly (3.43) and found the health system successful (3.09) at a moderate level.

Radiology physicians stated that they had sufficient information to diagnose COVID-19 cases $(3,63)$; keep up-to-date scientific information on the pandemic $(3,61)$; that they could not hold routine scientific meetings and seminars $(4,01)$; that they are in positive solidarity with their colleagues (3.87); they obtained a separate informed consent about COVID-19 from patients $(3,16)$; they stated that unnecessary thorax CT demands increased $(4,51)$ and they made the most thorax $\mathrm{CT}$ evaluation in the pandemic $(4,42)$.

According to the answers they gave to the openended question of radiology physicians, "Write down the countries you find successful or unsuccessful in combating the pandemic"; successful countries; Germany (53), South Korea (51), China (35) and Turkey (29); failed countries; They expressed it as Italy (58), Spain (54), England (22) and USA (21).
Anxiety was not detected in $44.6 \%$ of the radiology physicians during the pandemic process. Mild anxiety was detected in $31.3 \%$ of the radiologists, moderate in $16.9 \%$ and severe anxiety in $7.2 \%$. The data about the measurement of anxiety levels of radiologists during the pandemic process are shown in Table 3.

A weak linear relationship was found between the changes in the functioning of radiology clinics and the personal concerns of radiology physicians at the $p=0.05$ error level (0.224). A weak linear relationship was found between the personal anxiety factor of the radiology physicians, the clinical approach and the factor of combating the pandemic at the $\mathrm{P}=0.01$ error level (0.336). It was found that there is a moderate linear relationship (0.515) between the personal anxiety and anxiety level of radiologists. According to the correlation analysis results, the disruption in the functioning of radiology clinics due to the pandemic increases the personal concerns of radiology physicians, the increase in the personal anxiety of radiology physicians, increases the anxiety levels of the physicians, at the same time changes the clinical approach and increases the fight against the pandemic. The data of the relationship between the factors of the scale of the functioning of radiology clinics during the pandemic process and the anxiety scale of radiology physicians are given in Table 4.

Table 1. Frequency table of the participants descriptive variables

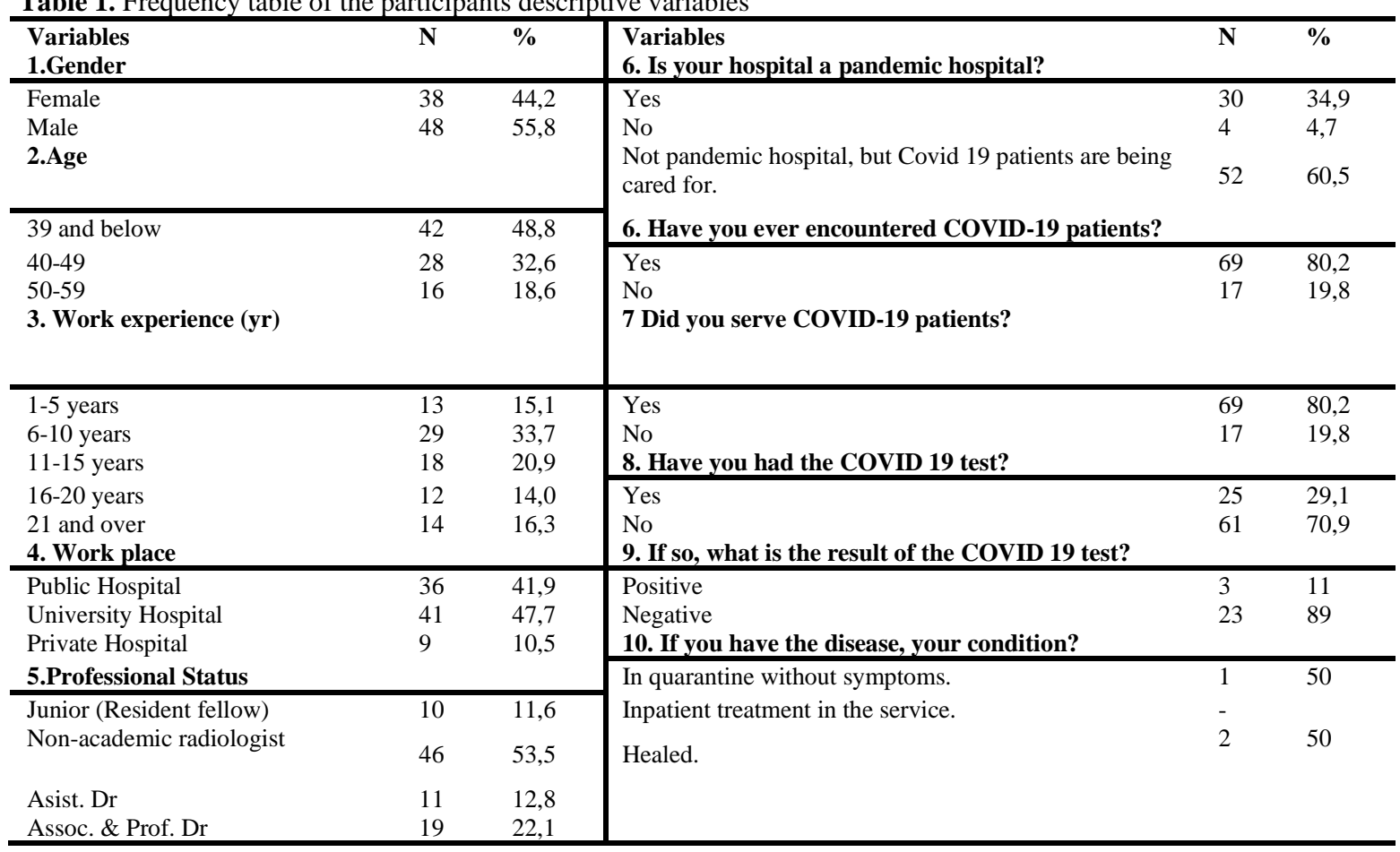


Table 2: Frequency distribution of the scale of the clinical activities of radiology in COVID-19 pandemic

\section{Investigation of the Effects of the COVID-19 Pandemic on the \\ Activities of the Radiology Clinic

\begin{tabular}{|c|c|c|c|}
\hline I never agree & I do not agree & I partially & I Agree \\
\hline
\end{tabular}

Statements

1. Clinical Functioning

\begin{tabular}{llllllllllll}
\hline $\mathrm{n}$ & $\%$ & $\mathrm{n}$ & $\%$ & $\mathrm{n}$ & $\%$ & $\mathrm{n}$ & $\%$ & $\mathrm{n}$ & $\%$ & &
\end{tabular}

\begin{tabular}{|c|c|c|c|c|c|c|c|c|c|c|c|c|}
\hline We cannot continue routine patient admissions. & 14 & 16,3 & 13 & 15,1 & 9 & 10,5 & 18 & 20,9 & 32 & 37,2 & 3,47 & 1,51 \\
\hline $\begin{array}{l}\text { We postpone interventional radiology } \\
\text { procedures. }\end{array}$ & 5 & 5,8 & 12 & 14,0 & 20 & 23,3 & 27 & 31,4 & 21 & 24,4 & 3,55 & 1,20 \\
\hline We postpone routine ultrasound applications. & 6 & 7,0 & 11 & 12,8 & 16 & 18,6 & 30 & 34,9 & 23 & 26,7 & 3,61 & 1,20 \\
\hline $\begin{array}{l}\text { We only accept emergency cases and oncology } \\
\text { patients. }\end{array}$ & 11 & 12,8 & 6 & 7,0 & 4 & 4,7 & 13 & 15,1 & 52 & 60,5 & 4,03 & 1,45 \\
\hline $\begin{array}{l}\text { We postpone all radiological procedures, } \\
\text { except for coronavirus cases. }\end{array}$ & 33 & 38,4 & 10 & 11,6 & 14 & 16,3 & 24 & 27,9 & 5 & 5,8 & 2,51 & 1,39 \\
\hline $\begin{array}{l}\text { Since the routine radiological procedures of } \\
\text { outpatients are delayed, the diagnosis } \\
\text { processes of the patients are delayed. }\end{array}$ & 3 & 3,5 & 6 & 7,0 & 14 & 16,3 & 39 & 45,3 & 23 & 26,7 & 3,85 & 1,01 \\
\hline $\begin{array}{l}\text { We help our patients with tele-medicine } \\
\text { techniques }\end{array}$ & 8 & 9,3 & 7 & 8,1 & 9 & 10,5 & 27 & 31,4 & 35 & 40,7 & 3,86 & 1,29 \\
\hline $\begin{array}{l}\text { I am assigned to the processes of coronavirus } \\
\text { patients outside of radiology expertise. }\end{array}$ & 57 & 66,3 & 2 & 2,3 & 7 & 8,1 & 11 & 12,8 & 9 & 10,5 & 1,98 & 1,49 \\
\hline Factor 2: Personal anxiety & & & & & & & & & & & 3,74 & 0,97 \\
\hline I am highly anxious about getting the disease. & 5 & 5,8 & 8 & 9,3 & 11 & 12,8 & 33 & 38,4 & 28 & 32,6 & 3,83 & 1,16 \\
\hline $\begin{array}{l}\text { Requesting USG for patients with COVID-19 } \\
\text { with different indications increases my stress. }\end{array}$ & 3 & 3,5 & 4 & 4,7 & 11 & 12,8 & 30 & 34,9 & 36 & 41,9 & 4,09 & 1,03 \\
\hline $\begin{array}{l}\text { High expectations of clinicians in diagnosing } \\
\text { coronavirus patients with CT causes stress. }\end{array}$ & 7 & 8,1 & 11 & 12,8 & 13 & 15,1 & 35 & 40,7 & 19 & 22,1 & 3,56 & 1,20 \\
\hline $\begin{array}{l}\text { The rapid deterioration of the follow-up CT of } \\
\text { coronavirus patients causes serious anxiety in } \\
\text { me. }\end{array}$ & 8 & 9,3 & 5 & 5,8 & 13 & 15,1 & 39 & 45,3 & 21 & 24,4 & 3,69 & 1,17 \\
\hline $\begin{array}{l}\text { It worries me that I am assigned to the } \\
\text { processes of coronavirus patients. }\end{array}$ & 16 & 18,6 & 5 & 5,8 & 7 & 8,1 & 29 & 33,7 & 24 & 27,9 & 3,49 & 1,47 \\
\hline Factor 3: Clinical Approach and Combat & & & & & & & & & & & 3,67 & 0,7 \\
\hline $\begin{array}{l}\text { In-house information processes regarding } \\
\text { coronavirus are carried out effectively. }\end{array}$ & 6 & 7,0 & 6 & 7,0 & 35 & 40,7 & 23 & 26,7 & 16 & 18,6 & 3,43 & 1,09 \\
\hline $\begin{array}{l}\text { We obtain separate consent for coronavirus } \\
\text { from patients with interventional procedures. }\end{array}$ & 13 & 15,1 & 9 & 10,5 & 29 & 33,7 & 15 & 17,4 & 17 & 19,8 & 3,16 & 1,31 \\
\hline $\begin{array}{l}\text { Unnecessary CT demands are increasing in } \\
\text { order not to bypass the diagnosis. }\end{array}$ & 3 & 3,5 & 0 & 0 & 3 & 3,5 & 23 & 26,7 & 56 & 65,1 & 4,51 & 0,86 \\
\hline $\begin{array}{l}\text { We mostly evaluate thorax CT, in daily } \\
\text { routine. }\end{array}$ & 2 & 2,3 & 1 & 1,2 & 3 & 3,5 & 31 & 36,0 & 47 & 54,7 & 4,42 & 0,82 \\
\hline $\begin{array}{l}\text { We have enough personal protective } \\
\text { equipment }\end{array}$ & 7 & 8,1 & 17 & 19,8 & 25 & 29,1 & 25 & 29,1 & 12 & 14,0 & 3,20 & 1,15 \\
\hline $\begin{array}{l}\text { We use personal protective equipment } \\
\text { correctly. }\end{array}$ & 3 & 3,5 & 9 & 10,5 & 33 & 38,4 & 30 & 34,9 & 11 & 12,8 & 3,43 & 0,96 \\
\hline $\begin{array}{l}\text { We are in a positive solidarity with our } \\
\text { colleagues }\end{array}$ & 3 & 3,5 & 4 & 4,7 & 21 & 24,4 & 31 & 36,0 & 27 & 31,4 & 3,87 & 1,02 \\
\hline $\begin{array}{l}\text { We cannot conduct our scientific meeting- } \\
\text { seminar programs }\end{array}$ & 12 & 14,0 & 4 & 4,7 & 4 & 4,7 & 17 & 19,8 & 49 & 57,0 & 4,01 & 1,44 \\
\hline $\begin{array}{l}\text { I have enough knowledge and equipment to } \\
\text { diagnose coronavirus }\end{array}$ & 4 & 4,7 & 11 & 12,8 & 16 & 18,6 & 36 & 41,9 & 19 & 22,1 & 3,63 & 1,10 \\
\hline $\begin{array}{l}\text { We can follow current scientific data on } \\
\text { coronavirus }\end{array}$ & 9 & 10,5 & 7 & 8,1 & 13 & 15,1 & 36 & 41,9 & 21 & 24,4 & 3,61 & 1,23 \\
\hline The health system is successful & 6 & 7,0 & 26 & 30,2 & 16 & 18,6 & 28 & 32,6 & 9 & 10,5 & 3,09 & 1,16 \\
\hline
\end{tabular}


Table 3. Evaluation of radiology physicians' back anxiety scales

\begin{tabular}{lll}
\hline Back Anxiety Scale & N & $\%$ \\
\hline None & 37 & 44,6 \\
Mild & 26 & 31,3 \\
Moderate & 14 & 16,9 \\
Severe & 6 & 7,2 \\
\hline
\end{tabular}

Table 4: Relationship between factors of radiology clinical activity scale and back anxiety scale

\begin{tabular}{|c|c|c|c|c|}
\hline Factors & $\begin{array}{c}\text { Clinical } \\
\text { Functioning }\end{array}$ & $\begin{array}{l}\text { Personal } \\
\text { Anxiety }\end{array}$ & $\begin{array}{c}\text { Clinical } \\
\text { Approach and } \\
\text { Combat }\end{array}$ & Anxiety \\
\hline Clinical Functioning & 1 & & & \\
\hline Personal Anxiety &, $224(*)$ & 1 & & \\
\hline $\begin{array}{l}\text { Clinical Approach and } \\
\text { Combat }\end{array}$ &, 049 &, $336(* *)$ & 1 & \\
\hline Anxiety &, 107 &, $515(* *)$ &, 176 & 1 \\
\hline
\end{tabular}

\section{Discussion}

Throughout history, pandemics have been observed to have significant effects on societies, leading to many psychological, social and economic consequences. Similarly, the COVID-19 outbreak has become a serious global public health issue, the effects of which will be felt in the future. Probably the most affected part of the community is frontline healthcare professionals. In this study, changes in the functioning of the radiology clinics in Turkey through pandemic period was shown and the level of anxiety caused by these existing changes among radiologists was determined. A significant relationship was observed between the change in clinical functioning and the level of anxiety.

During this acute and unexpected COVID-19 pandemic, priorities of Turkish health system and organization of hospitals were revised. Regardless of their specialty, all physicians were re-assigned to outpatient clinics, services and intensive care units in order to take care of COVID-19 patients. As a result, radiology physicians, like all other healthcare professionals, were exposed to an aggravating risk of contamination. In a study conducted by Lai et al., It was shown that healthcare workers working in pandemic clinics of Wuhan city reported serious psychological symptoms (11). In a survey among Turkish neurosurgeons during the Covid 19 pandemic process, Yilmaz et al. reported that, an increase in anxiety level was found (12). Another study conducted in France found that symptoms of depression, anxiety, and insomnia were common in more than a third of radiologists in France during the pandemic (13).
In our study parallel with the literature, it was observed that radiologists expressed moderate to high levels of anxiety and stress from being caught with COVID-19 disease, from USG applications performed to COVID-19 positive patients for noncovid reasons and from being assigned to COVID-19 patient care units. Despite the increased anxiety rates, the rate of severe anxiety according to Back Anxiety Scale was found to be $7 \%$. In a study involving all healthcare professionals (doctor, nurse, technician) during the Covid 19 pandemic, a higher level of personal anxiety and anxiety was found (14). This situation can be expressed as the radiology specialists mostly working in the reporting part, and the employees who come into close contact with the patient are technicians and nurses (15).

During the Covid 19 pandemic, exposure or fear of exposure to the virus in terms of psychologic symptoms such as anxiety and insomnia has been identified as an important risk factor (11). In our study, $80.2 \%$ of the radiologists who participated in the questionnaire stated that they encountered patients with COVID-19 and 12\% tested positive. Studies have found that factors such as working in COVID-19 outpatient clinics and services increase psychological symptoms (11). In addition, it has been reported that the lack of protective equipment is of concern and more than $70 \%$ of actively working radiologists worldwide lack access to protective equipment (16-18). In our study, different from the data in the literature, radiologists stated that they had enough personal protective equipment $(3,20)$ and used personal protective equipment correctly $(3,43)$.

Some measures have been taken in both public hospitals and private hospitals to prevent the spread 
of the Corona virus. In this context, non-emergency patient examinations were suspended. Regulations have also been made in the functioning of radiology clinics. In our study, the participants stated that routine USG and interventional radiology procedures were not performed in their clinics, and that emergency and cancer patients continued their procedures. On the other hand, due to studies showing that thorax CT can help in the diagnosis of COVID 19, the number of thorax CT scans has increased significantly $(9,19,20)$. Although it was not recommended by radiology authorities, the widespread use of thorax CT as an auxiliary diagnostic method in the triage of COVID 19 has increased the workload $(21,22)$. In our study, $90 \%$ of the participants stated that they mainly evaluated thorax CT examinations in their daily radiology practice, and $91 \%$ of the participants stated that unnecessary thorax CT requests were made in order not to miss the diagnosis of COVID-19. They also stated that they were concerned that their colleagues had high expectations for the diagnosis of COVID19. Studies with CT in the diagnosis of COVID-19 and treatment follow-up have shown rapid radiological deterioration (23). In our study, participants stated that the rapid deterioration of CT in COVID-19 patients increased their anxiety.

Studies have reported important abrupt changes in the health system and the function of clinics that make up the health system during the pandemic period $(12,24,25)$. In our study, radiologists listed the changes related to clinical functioning apart from increased thorax CT numbers as follows; They follow up-to-date scientific data on COVID 19, are unable to hold routine face-to-face scientific meetings and seminars, they are more in solidarity with their colleagues and receive informed consent about COVID-19 separately from patients.

Our study has limitations. First, this study is a questionnaire filled out by a limited number of radiologists and may not represent other radiology professionals and all radiology departments. Finally, this was a cross-sectional study and no follow-up was done. Personal concerns and anxieties may progress differently in different time periods of the pandemic. For this reason, there is a need for repeated studies with the same and larger participant groups at different times.

In our study it was shown that there were significant changes in the functioning of radiology clinics especially related with increased thorax CT scans at the beginning of the COVID-19 pandemic and that the anxiety levels of radiologists increased due to the pandemic.
In conclusion, it is important to adapt to changes in clinical functions and to take necessary precautions for the transmission of infection, which causes anxiety in radiology specialists. Also, it is an important issue to take necessary forward measures regarding the diagnosis and interventional procedures of outpatients.

\section{Conclusion}

- It was understood that the radiologists working during the pandemic had a high level of personal anxiety and worked under stress in Turkey.

- The risk of developing COVID-19 disease, high expectations of colleagues about the diagnosis of COVID-19 with thorax CT, rapid deterioration in the CT of COVID-19 patients and being assigned to COVID-19 patient care units were stated as conditions that lead to increased anxiety and stress levels.

- They stated that unnecessary thorax CT demands increased, and they made the most thorax CT evaluation in the daily routine.

Ethics Committee Approval: Appropriate permission for the study was obtained from the Committee of Ethics of Ataturk University (approval no: B.30.2.ATA.0.01.00/119).

Peer-review: Externally peer-reviewed.

\section{Author Contributions:}

Concept: H.A, S.B, Design: H.A, S.B, Literature Search: H.A, S.B, Data Collection and Processing: H.A, S.B, Analysis or Interpretation: H.A, S.B, Writing: H.A, S.B.

Conflict of Interest: No conflict of interest was declared by the authors.

Financial Disclosure: The authors declared that this study hasn't received no financial support.

\section{References}

1. Wang C, Horby PW, Hayden FG, Gao GF. A novel coronavirus outbreak of global health concern. Lancet 2020; 395: 470-73

2. Yi Y, Lagniton PNP, Ye S, Enqin L, Ren-He X. COVID-19: what has been learned and to be learned about the novel coronavirus disease. Int $\mathrm{J}$ Biol Sci 2020; 16: 1753-1766

3. Mahase E. China coronavirus: WHO declares international emergency as death toll exceeds 200. BMJ DOI :10.1136/bmj.2020. 408.31 Jan 2020.

4. Bostan S, Erdem R, Ozturk YE, Kilic T, Yilmaz A: The Effect of COVID-19 Pandemic on the Turkish Society. Electronic Journal of General Medicine 2020; 17:1-6 
5. Singhal T. A review of coronavirus disease- 2019 (COVID-19). Indian J Pediatr, 2020; 87: 281-86

6. Peng X, Xu X, Li Y, Cheng L, Zhou XD, Ren B. Transmission routes of 2019-nCoV and controls in dental practice. Int J Oral Sci 2020; 12: 1-9

7. Cohen J, Normile D: New SARS-like virus in China triggers alarm. Science 2020; 367: 234-35

8.https://www.worldometers.info/coronavirus/\#coun tries

9. Fang Y, Zhang H, Xie J, Lin M, Ying L, Pang P, Ji W. Sensitivity of chest CT for COVID-19: comparison to RT-PCR. Radiology 2020; 296: 115-117

10.Huang JZ, Han MF, Luo TD, Ren AK, Zhou XP. Mental health survey of 230 medical staff in a tertiary infectious disease hospital for COVID-19. Zhonghua Lao Dong Wei Sheng Zhi Ye Bing Za Zhi 2020; 38: 192-95

11.Lai J, Ma S, Wang Y, Cai Z, Hu J, Wei N, et al. Factors associated with mental health outcomes among health care workers exposed to Coronavirus Disease. JAMA 2019 DOI:10.1001/jamanetworkopen.2020. Published online 23 March 2020

12. Yilmaz A, Karakoyun DO, Isik HS, Bostan S. The Effect of the COVID-19 Pandemic on Functioning of Neurosurgery Clinics and the Anxiety Levels of Neurosurgeons in Turkey. Turkish Neurosurgery 2020; $30: 1-8$

13.Florin M, Pinar U, Chavigny E, Bouaboula M, Jarboui L, Coulibaly A, et al. Socio-economic and psychological impact of the COVID-19 outbreak on private practice and public hospital radiologists. European Journal of Radiology 2020 DOI: $\quad 10.1016 /$ j.ejrad.109285.2020.10928.Published online 15 Sep 2020

14.Bostan S, Akbolat M, Kaya A, Ozata M, Gunes D. Assessments of Anxiety Levels and Working Conditions of Health Employees Working in COVID-19 Pandemic Hospitals Electronic Journal of General Medicine 2020; 17: 246

15.Huang L, Wang Y, Liu J, Ye P, Chen X, Xu H, et al. Factors Influencing Anxiety of Health Care Workers in the Radiology Department with High Exposure Risk to COVID-19, Med Sci Monit. 2020; 26: e926008-1-e926008-9

16. Cheng VCC, Lau SKP, Woo PCY, Yuen KY. Severe acute respiratory syndrome coronavirus as an agent of emerging and reemerging infection. Clin. Microbiol. Rev 2007; 20: 660-694.

17. Shanafelt T, Ripp J, Trockel M, Understanding and addressing sources of anxiety among health care professionals during the COVID-19 pandemic. JAMA 2020;323:2133-2134
18.Fang Y, Nie Y, Penny M: Transmission dynamics of the COVID-19 outbreak and effectiveness of government interventions: A data-driven analysis. J Med Virol 2020; 92: 645-59

19.Bai HX, Hsieh B, Xiong Z, Halsey K, Choi JW, Tran TML, et al. Performance of radiologists in differentiating COVID-19 from viral pneumonia on chest CT. Radiology 2020 DOI: 10.1148/radiol.2020200823. Published online 10 Mar 2020.

20.Kanne JP, Little BP, Chung JH, Elicker BM, Ketai LH. Essentials for radiologists on COVID-19: an update-radiology scientific expert panel, Radiology $2020 \quad$ DOI: 10.1148/radiol.2020200527. Published online 27 Feb 2020.

21.Raptis CA, Hammer MM, Short RG, Shah A, Bhalla S, Bierhals AJ, et al. Chest CT and Coronavirus Disease (COVID-19): A Critical Review of the Literature to Date. AJR 2020; 215:839-842

22.Rubin GD, Ryerson CJ, Haramati LB, Sverzellati N, Kanne JP, Raoof S, et al. The Role of Chest Imaging in Patient Management during the COVID-19 Pandemic: A Multinational Consensus Statement from the Fleischner Society. Radiology 2020; 296:172-180

23. Wei J, Xu H, Xiong J, Shen Q, Fan B, Ye C, et al. 2019 Novel Coronavirus (COVID-19) Pneumonia: Serial Computed Tomography Findings. Korean J Radiol 2020; 21:501-504

24.McManus S, Bebbington P, Jenkins R, Brugha T. Mental health and wellbeing in England: Adult Psychiatric Morbidity Survey 2014; Cited May 2020. Available from. https://files.digital.nhs.uk/pdf/q/3/mental_health_ and_wellbeing_in_england_full_report.pdf.

25.Beck AT, Epstein N, Brown G, Steer RA. An inventory for measuring clinical anxiety: psychometric properties. J Consult Clin Psychol 1988;56: 893-897 